\title{
Measles virus nucleocapsid protein increases osteoblast differentiation in Paget's disease
}

\author{
Jumpei Teramachi, ${ }^{1}$ Yuki Nagata, ${ }^{1}$ Khalid Mohammad, ${ }^{2}$ Yuji Inagaki, ${ }^{1}$ Yasuhisa Ohata, ${ }^{1}$ Theresa Guise, ${ }^{2}$ Laëtitia Michou, ${ }^{3}$ \\ Jacques P. Brown, ${ }^{3}$ Jolene J. Windle, ${ }^{4}$ Noriyoshi Kurihara, ${ }^{1}$ and G. David Roodman ${ }^{1,5}$ \\ 'Department of Hematology-Oncology and '2Department of Endocrinology, Department of Medicine, Indiana University, Indianapolis, Indiana, USA. ${ }^{2}$ Laval University, CHUQ (CHUL) Research Center, Quebec \\ City, Quebec, Canada. ${ }^{4}$ Human and Molecular Genetics, Virginia Commonwealth University (VCU), Richmond, Virginia, USA. ${ }^{5}$ Roudebush VA Medical Center, Indianapolis, Indiana, USA.
}

\begin{abstract}
Paget's disease $(P D)$ is characterized by focal and dramatic bone resorption and formation. Treatments that target osteoclasts (OCLs) block both pagetic bone resorption and formation; therefore, $\mathrm{PD}$ offers key insights into mechanisms that couple bone resorption and formation. Here, we evaluated OCLs from 3 patients with $\mathrm{PD}$ and determined that measles virus nucleocapsid protein (MVNP) was expressed in $70 \%$ of these OCLs. Moreover, transgenic mice with OCL-specific expression of MVNP (MVNP mice) developed PD-like bone lesions that required MVNP-dependent induction of high IL-6 expression levels in OCLs. In contrast, mice harboring a knockin of p62 ${ }^{\mathrm{P} 394 \mathrm{~L}}$ (p62-KI mice), which is the most frequent PD-associated mutation, exhibited increased bone resorption, but not formation. Evaluation of OCLs from MVNP, p62-KI, and WT mice revealed increased IGF1 expression in MVNP-expressing OCLs that resulted from the high IL-6 expression levels in these cells. IL-6, in turn, increased the expression of coupling factors, specifically ephrinB2 on OCLs and EphB4 on osteoblasts (OBs). IGF1 enhanced ephrinB2 expression on OCLs and OB differentiation. Importantly, ephrinB2 and IGF1 levels were increased in MVNP-expressing OCLs from patients with PD and MVNP-transduced human OCLs compared with levels detected in controls. Further, anti-IGF1 or anti-IGF1R blocked Runx2 and osteocalcin upregulation in OBs cocultured with MVNP-expressing OCLs. These results suggest that in PD, MVNP upregulates IL-6 and IGF1 in OCLs to increase ephrinB2-EphB4 coupling and bone formation.
\end{abstract}

\section{Introduction}

Paget's disease (PD) is the most exaggerated example of coupled bone remodeling, with highly localized areas of increased bone resorption, accompanied by exuberant new bone formation (1). The rapid, excessive, focal new bone deposition in PD results in woven bone that is much weaker, can bow and cause bone deformity, fracture, skull thickening, bone pain, secondary osteoarthritis, and nerve root compression (2). The primary cellular abnormality in PD resides in the osteoclast (OCL) (3). OCLs are increased in number and size and express a pagetic phenotype that distinguishes them from normal OCLs (4), including hypermultinucleation, increased TAF12 levels (a coactivator of VDRmediated transcription), and increased $1,25-(\mathrm{OH})_{2} \mathrm{D}_{3}$ and RANKL responsivity (5-7). Further, OCLs in PD secrete high levels of IL-6, which are detectable in the marrow and peripheral blood of patients with PD (8). OCLs drive the increased bone formation in $\mathrm{PD}$, because treatment with bisphosphonates, which target OCL activity, reverses new pagetic bone formation (2), suggesting that PD offers key insights into the process of resorption and formation coupling. However, the mechanisms responsible for the increased bone formation in PD have not been elucidated.

Genetic and environmental factors contribute to the pathogenesis of PD. The most frequent mutations linked to PD are in the SQSTM1/p62 gene, in particular p62 $2^{\mathrm{P} 392 \mathrm{~L}}$, which is found in $30 \%$ of patients with hereditary PD and $10 \%$ of sporadic cases

Conflict of interest: G.D. Roodman is a consultant to Amgen. Submitted: March 20, 2015; Accepted: December 18, 2015.

Reference information: / Clin Invest. 2016;126(3):1012-1022. doi:10.1172/JCI82012.
(9-11). However, mutations like p62 ${ }^{\mathrm{P} 392 \mathrm{~L}}$ are apparently insufficient to induce PD, since some individuals harboring p62 mutations never develop the disease (10). Further, mice with a germline p62 ${ }^{\mathrm{P} 394 \mathrm{~L}}$ mutation (p62-knockin [p62-KI] mice), the murine equivalent of human $\mathrm{p} 62^{\mathrm{P} 392 \mathrm{~L}}$, exhibit increased OCL numbers but do not develop the markedly enhanced bone formation characteristic of PD (12). These results suggest that genetic factors increase OCLs, but environmental or other factors are also required for the increased bone formation that occurs in PD.

We previously found that OCLs from $70 \%$ of patients with PD express the measles virus nucleocapsid protein (MVNP) gene, and transgenic mice with MVNP targeted to OCLs (MVNP mice) develop OCLs and bone lesions that are characteristic of PD (13). Further, p62-KI mice bred with MVNP mice (p62-KI MVNP mice) develop greater numbers of pagetic-like OCLs and more dramatic bone lesions than do MVNP mice (13). Importantly, loss of IL-6 expression in MVNP mice abrogated both the production of pagetic-like OCLs and increased bone formation in vivo (13).

Normal bone resorption and formation are tightly linked, with bone formation occurring only at sites of previous bone resorption. This coupling of bone remodeling is dependent on communication between OCLs and osteoblasts (OBs) (14). Eph receptor expression on OBs and ephrins on OCLs and OBs have been implicated as major regulators of coupling (15). Ephs and ephrins are cell-surface molecules that signal bidirectionally and play major roles in tumor progression, angiogenesis, cell migration, and morphogenesis (16). Irie et al. reported that bidirectional signaling through ephrinA2/EphA2 enhances osteoclastogenesis and suppresses OB differentiation (17). In contrast, ephrinB and EphB 
receptors promote skeletal development (16). Zhao and coworkers showed that bidirectional ephrinB2/EphB4 signaling regulates bone remodeling (15), that OCLs express the NFATc1 target gene ephrinB2 and OBs express its receptor EphB4, and that transgenic mice with increased EphB4 signaling in OBs had enhanced bone mass (15). Additionally, reverse signaling through ephrinB2 on OCLs suppresses OCL differentiation by inhibiting the c-Fos/ NFATc1 cascade (15). Although ephrinB1 expression on OCLs also stimulates Eph signaling in OBs, ephrinB2 is specific for EphB4 (15). EphrinB2 can also be expressed in response to parathyroid hormone (PTH) in OBs, where it interacts with EphB4 to increase OB differentiation $(18,19)$. These data suggest that ephrinB2/ EphB4 signaling plays a major role in coupling bone resorption to new bone formation.

Since PD represents the most exaggerated form of coupled bone formation, we determined the expression levels of ephrins and their receptors on OCLs and OBs from MVNP, p62-KI MVNP, p62-KI, and WT mice. Only MVNP and p62-KI MVNP, but not p62-KI, mice exhibited elevated levels of ephrinB2 on OCLs and EphB4 on OBs compared with expression levels detected in WT mice. A preliminary gene expression-profiling study of highly purified OCLs from MVNP, p62-KI, and WT mice showed that OCLs from MVNP mice expressed elevated levels of Igf1 mRNA compared with WT mice, while OCLs from p62-KI mice did not. We further found that IL-6 regulated the increased expression of IGF1 protein in OCLs from MVNP mice, and IL-6 and IGF1, in turn, increased the expression of ephrinB2 on OCLs. IL-6 also increased EphB4 on OBs, while IGF1 enhanced $\mathrm{OB}$ differentiation.

\section{Results}

EphrinB2 and EphB4 levels are increased in bone extracts and in isolated $O C L s$ and $O B s$, respectively, from MVNP mice. To determine the basis for the OCL-driven increase in bone formation found in MVNP, but not p62-KI, mice, we tested total bone extracts as well as isolated OCLs and OBs from WT, MVNP, and p62-KI mice for the expression of known coupling factors that link OCL activity to bone formation. We found that total bone lysates from MVNP, but not p62-KI, mice had increased expression of ephrinB2 and EphB4 (Figure 1A). The increased ephrinB2 and EphB4 levels were only detectable in MVNP mice older than 6 months (Figure 1B), consistent with our findings that pagetic-like lesions are undetectable in these mice until 8 to 12 months of age. In contrast, expression levels of other proteins implicated in coupling were unchanged, including several other ephrin and Eph subtypes (Figure 1A) and neuropilin 1 (Supplemental Figure 1; supplemental material available online with this article; doi:10.1172/JCI82012DS1) in bones from MVNP and p62-KI mice compared with those from WT mice. Semaphorin 3A was increased in OCLs and OBs from both p62-KI and MVNP mice (Supplemental Figure 1), suggesting that it was not responsible for the increased bone formation in MVNP mice. Further, vertebral sections from 12-month-old mice were processed for IHC, which showed that ephrinB2 expression on OCLs and EphB4 expression on OBs from MVNP mice had increased staining compared with that seen in WT and p62-KI mice (Figure 1C). Western blot analysis of lysates from OCLs derived from

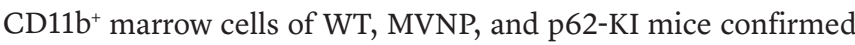
that ephrinB2 expression was greatly increased on OCLs derived from MVNP mice. Similarly, we observed that expression of EphB4 was only increased in OBs derived from tibial explants of MVNP mice (data not shown). Analysis of OCLs derived from CD11b ${ }^{+}$ cells of WT, MVNP, p62-KI, and p62-KI MVNP mice showed that ephrinB2 was only increased on OCLs expressing MVNP and was not enhanced by coexpression of p62 ${ }^{\mathrm{P} 94 \mathrm{~L}}$ (Figure 1D). We then compared ephrinB2 expression on OCLs derived from PD patients expressing MVNP and the p62 $2^{\mathrm{P} 392 \mathrm{~L}}$ mutation or only harboring the p62 $2^{\mathrm{P} 392 \mathrm{~L}}$ mutation with expression levels in OCLs from normal controls. OCLs from patients who expressed MVNP (patients 1 and 2) (Supplemental Figure 2) had higher ephrinB2 levels than did a PD patient harboring $\mathrm{p} 62^{\mathrm{P} 392 \mathrm{~L}}$ who did not express MVNP (patient 3) and normal controls (Figure 2).

$M V N P$-expressing OCLs increase $O B$ differentiation via forward signaling through EphB4. We next determined the effects of ephrinB2 or EphB4 signaling on OCLs and OBs by either stimulating EphB4 signaling in OBs from WT or MVNP mice with ephrinB2-Fc $(5 \mu \mathrm{g} / \mathrm{ml})$, or treating bone cell cocultures from MVNP or WT mice with EphB4-Fc, which increases reverse signaling through ephrinB2 and blocks EphB4 signaling. We found that stimulation of EphB4 with ephrinB2-Fc increased phosphorylated ERK1/2 (p-ERK1/2) signaling in OBs from MVNP mice (Figure $3 \mathrm{~A}$ ) and enhanced $\mathrm{OB}$ differentiation and calcification to a greater extent in OB cultures from MVNP mice than in cultures from WT mice (Figure 3B). Blocking EphB4 and stimulating reverse signaling by ephrinB2 with EphB4-Fc $(5 \mu \mathrm{g} / \mathrm{ml})$ inhibited both OB and OCL differentiation, as assessed by Runx2 and NFATc1 levels, respectively (Figure 3C). OCL formation induced by either RANKL $(50 \mathrm{ng} / \mathrm{ml})$ or $1,25-(\mathrm{OH})_{2} \mathrm{D}_{3}\left(10^{-8} \mathrm{M}\right)$ treatment of $\mathrm{CD}_{11} \mathrm{~b}^{+}$cells from WT and MVNP mice was significantly blocked by 5 to $10 \mu \mathrm{g} / \mathrm{ml} \mathrm{EphB4-Fc} \mathrm{(Figure} \mathrm{3D).} \mathrm{Further,}$ EphB4-Fc $(10 \mu \mathrm{g} / \mathrm{ml})$ blocked bone resorption by OCLs cultured with RANKL or 1,25- $(\mathrm{OH})_{2} \mathrm{D}_{3}$ in WT and MVNP cultures (Figure $3 \mathrm{E}$ ) as well as expression of c-Fos, NFATc1, TRACP, cathepsin K, and Vav3 markers of OCL differentiation in RANKL-treated OCL precursors from WT and MVNP mice (Figure 3F).

$I L-6$ increases ephrinB2 and EphB4 expression on OCLs and $O B s$ from MVNP mice. Since loss of IL-6 prevents the development of pagetic-like OCLs and pagetic-like bone lesions in MVNP mice (13), we tested OCLs, OBs, and total bone lysates from WT, MVNP, MVNP $\mathrm{Il}^{-/}$, and $\mathrm{Il}^{-/-}$mice for expression of ephrinB2 and EphB4. Expression levels of ephrinB2 and EphB4 in total bone lysates from MVNP $\mathrm{Il6}^{-/}$and $\mathrm{Il6}^{-/-}$mice were decreased compared with levels in MVNP and WT lysates, respectively (Figure 4A). Analysis of OCLs derived from CD11 ${ }^{+}$cells from mice of each genotype showed that ephrinB2 expression was decreased on OCLs from WT and MVNP mice lacking IL-6 (Figure 4B). Loss of IL-6 also decreased expression of EphB4 in OBs derived from tibia explants from MVNP and WT mice (Figure 4C).

Given these results, we determined whether IL- 6 increased the expression of ephrinB2 on OCLs and EphB4 in OBs from WT mice. We found that IL-6 $(10 \mathrm{ng} / \mathrm{ml})$ also increased ephrinB2 expression on OCLs derived from CD11b cells from WT mice (Figure 4D) as well as EphB4 expression in WT OBs (Figure 4F). Interestingly, IL-6 only induced ephrinB2 expression in MVNP-transduced human OCLs (Figure 4E), suggesting that another factor induced by MVNP cooperates with IL- 6 to increase ephrinB2 expression in 
A

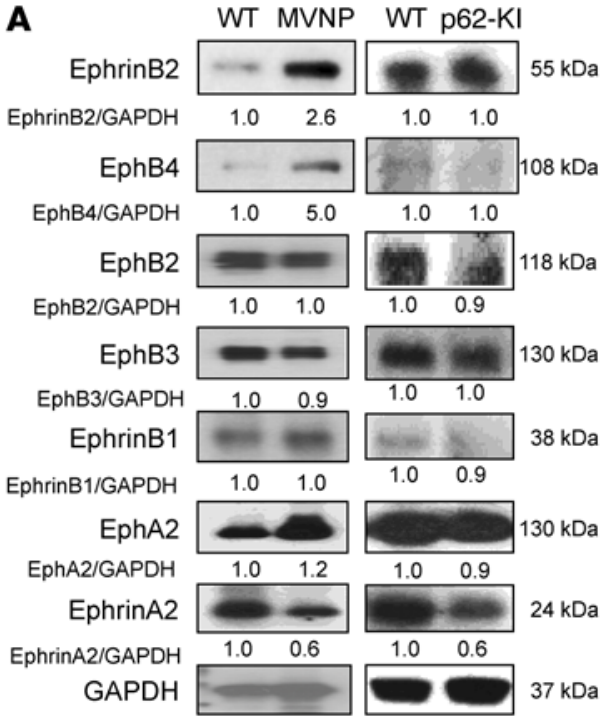

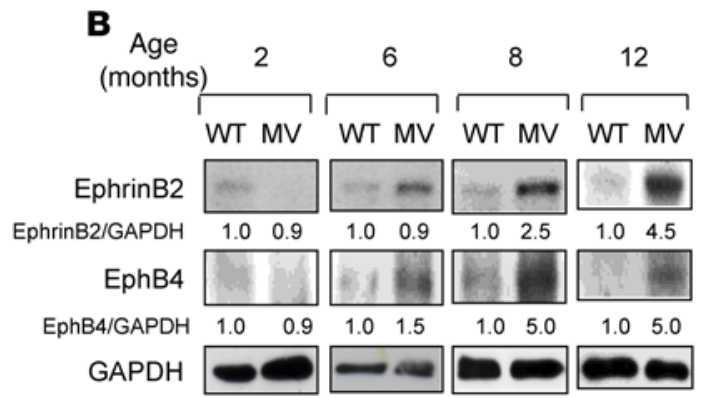

D

MVNP

C
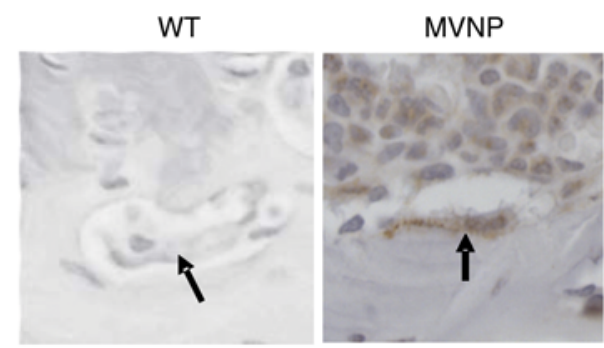

p62-KI
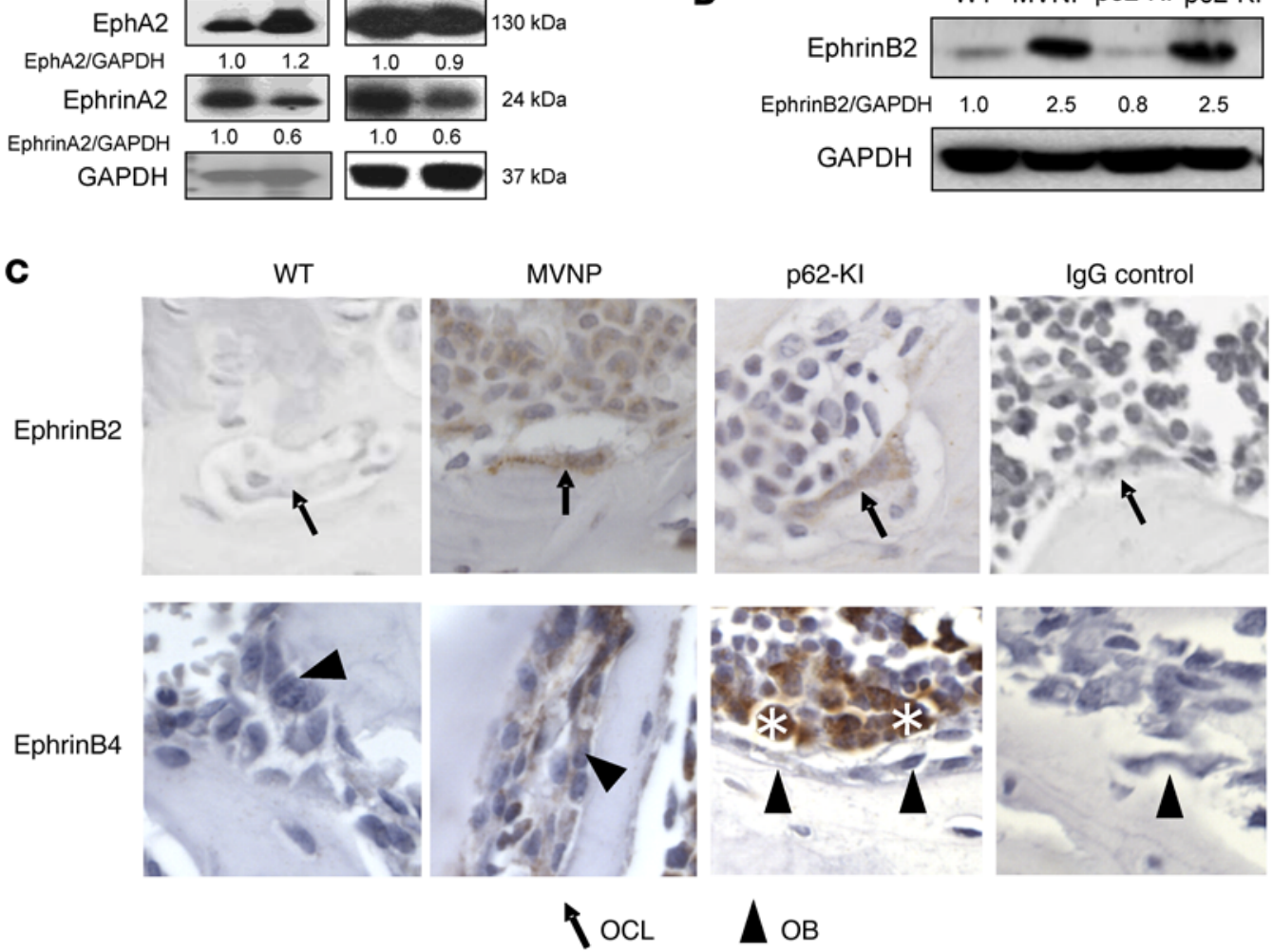

EphrinB2

Figure 1. Expression of ephrins and Ephs in WT, MVNP, p62-KI, and MVNP p62-KI mice. (A) Bone lysates from 8-month-old WT, MVNP, and p62-KI mice were assayed for ephrin and Eph protein expression. Results are representative of 3 biological replicates. (B) Bone lysates were obtained from 2- to 12-month-old mice and tested for ephrinB2 and EphB4 expression. Results are representative of 3 biological replicates. (C) Vertebral sections from 12-month-old mice were stained with anti-ephrinB2 and -EphB4 Abs as described in Methods. Results are representative of 3 to 7 biological replicates. OCLs from MVNP mice clearly stained for ephrinB2 compared with OCLs from p62-KI and WT mice, which showed minimal or negative staining. OBs from MVNP mice stained positively for EphB4 compared with OBs from WT and p62-KI mice. Scoring was based on staining intensity (positive or negative) and was performed by a blinded observer. Solid arrows point to OCLs, and arrowheads point to OBs. As previously reported, marrow cells (indicated by asterisks) also stained positively for EphB4 (33). Original magnification, $\times 400$. (D) OCLs derived from cultures of CD11b+ cells from 8-month-old mice were assayed for ephrinB2 as described in Methods. Results are representative of 3 biological replicates. The basal ratio of every molecule/loading control is shown as 1.0 for WT samples in $\mathbf{A}, \mathbf{B}$, and $\mathbf{D}$.

human OCLs. We next determined whether transgenic mice with increased IL-6 expression targeted to OCLs (TRACP-IL-6 mice) had increased ephrinB2 expression on their OCLs. OCL precursors from WT and TRACP-IL-6 mice were treated with RANKL to induce OCL differentiation, and the OCLs that formed were tested for ephrinB2 expression. We observed that OCLs derived from TRACP-IL-6 mice expressed higher levels of ephrinB2 compared with WT OCLs (Figure 4G).

IGF1 contributes to enhanced ephrinB2 production by OCLs. On the basis of the results shown in Figure 4E, we determined whether other factors induced by MVNP, in addition to IL-6, were involved in the enhancement of ephrinB2 on OCLs. We performed a preliminary gene expression-profiling experiment with highly purified OCLs derived from MVNP, p62-KI, and WT OCL precursors and found that IgfI mRNA expression was enhanced 2-fold in MVNP-expressing OCL precursors compared with those of the other genotypes (data not shown). This experiment suggested that MVNP induces IGF1 in OCL precursors.

To confirm these results, we measured IGF1 protein levels in total bone lysates from tibiae (Figure 5A) and OCLs formed from 


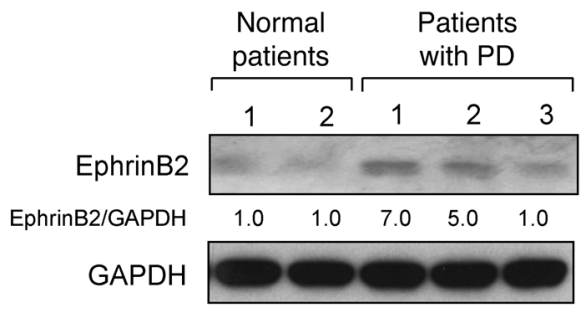

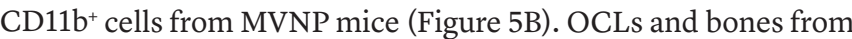
MVNP, but not p62-KI, mice expressed increased levels of IGF1 compared with levels detected in WT mice. Immunohistochemical analysis confirmed that IGF1 expression was elevated in OCLs from MVNP mice (Figure 5C). We next determined whether IGF1 expression was increased in OCLs from MVNP-expressing and non-MVNP-expressing PD patients harboring p62 ${ }^{\mathrm{P} 392 \mathrm{~L}}$ compared with normal controls. We found that IGF1 expression was markedly increased in OCLs from MVNP-expressing patients, but not in OCLs from an MVNP-negative patient (Figure 5D). IGF1 was not elevated in OBs from MVNP or p62-KI mice (data not shown). We measured IGF1 levels in media conditioned by equal numbers of purified OCLs derived from WT and MVNP mice and found that the MVNP-expressing OCLs secreted approximately 1,000 $\mathrm{pg} / \mathrm{ml}$ soluble IGF1 compared with the $100-200 \mathrm{pg} / \mathrm{ml}$ secreted by WT OCLs (Figure 5E).

We next determined whether IGF1 increased ephrinB2 and NFATc1 expression in OCLs by treating OCL precursors from WT and MVNP mice with 10 to $100 \mathrm{ng} / \mathrm{ml}$ IGF1. Treatment with 10 $\mathrm{ng} / \mathrm{ml}$ IGF1 remarkably increased ephrinB2 and NFATc1 expression by MVNP-expressing OCLs, but increased only NFATc1 expression in OCLs from WT mice (Figure 5F). Consistent with these results, treatment of MVNP-expressing OCLs with antiIGF1 decreased their ephrinB2 levels (Figure 5G). IGF1 receptor (IGF1R) expression levels were similar in WT and MVNPexpressing OCLs (Figure $5 \mathrm{H}$ ).

We then examined whether IGF1 induced differentiation of OB precursors from WT and MVNP mice treated with $10 \mathrm{ng} / \mathrm{ml}$ IGF1 for 3 days. IGF1 markedly increased Runx2 expression in OBs from MVNP mice, but had modest effects on EphB4 expression in OBs from WT or MVNP mice. Further, IGF1 modestly enhanced Runx2 in WT OBs (Figure 5I).

IL-6 induces IGF1 expression in MVNP-expressing OCLs. OCLs from patients with PD express high levels of IL-6 (8), and MVNP expression in OCLs induces high IL-6 expression levels that are essential for the formation of pagetic-like OCLs and bone lesions in MVNP-expressing mice (13). However, it is unknown whether IL-6 increases IGF1 expression, which would in turn increases ephrin B2 levels in MVNP mice. We found that IL-6 treatment of OCLs derived from CD11 $\mathrm{b}^{+}$OCL precursors from WT, MVNP, and p62-KI mice increased IGF1 expression in MVNP-expressing OCLs by 1.5 -fold, but had no effect on IGF1 expression in WT or p62-KI OCLs (Figure 6A). Further, IL-6 enhanced IGF1 expression (by 2.5 -fold) in MVNP-transduced, but not empty vectortransduced (EV-transduced), human OCLs (Figure 6B).

Next, we determined whether loss of IL- 6 affects IGF1 expression in WT, MVNP, MVNP $I l 6^{-/}$, and $I l 6^{-/}$mice OCLs. Loss of IL-6 blunted, but did not completely block, the increased IGF1 expres-
Figure 2. EphrinB2 expression in human OCLs from PD patients and normal donors. Purified OCLs derived from peripheral blood MNCs from normal donors and patients with PD were assayed for ephrinB2 by Western blotting. We previously reported that OCLs from patients 1 and 2 expressed MVNP (13). Results are representative of a single experiment performed in triplicate.

sion in OCLs from MVNP mice (Figure 6C). These results, taken together, suggest that IL-6, in combination with an additional factor(s) induced by MVNP, increases IGF1 in OCLs. The identity of this factor(s) is currently unknown.

IGF1 induced by MVNP in OCLs enhances OB differentiation. Since OCLs from MVNP, but not p62-KI, mice produce elevated levels of IGF1 (Figure 5, A and B), we assessed whether the expression of IGF1 by MVNP-expressing OCLs induced OB differentiation and whether these effects were blocked by anti-IGF1 or anti-IGF1R. As shown in Figure 7A, addition of OCLs from WT or MVNP mice to OBs from WT or MVNP mice increased EphB4 and osteocalcin (OCN) levels, with a greater induction of EphB4 and OCN by OCLs derived from MVNP mice. As expected, OBs from MVNP mice expressed higher levels of EphB4 and OCN, which were further increased by coculture with OCLs from MVNP and WT mice. To determine whether the enhanced effect of OCLs from MVNP mice on OCN produced by OBs from WT or MVNP mice was mediated by IGF1, we added anti-IGF1 or anti-IGF1R to these cocultures. As shown in Figure 7B, blocking IGF1 binding to its receptor significantly decreased OCN expression by WT and MVNP mouse OBs cocultured with OCLs from MVNP mice, but not in cocultures with OCLs from WT mice. As expected, the effects of blocking IGF1 were greater in cocultures of OCLs and OBs derived from MVNP mice. Furthermore, anti-IL- 6 and antiIL-6 receptor (anti-IL-6R) inhibited OB differentiation to the same extent in MVNP-OCL and MVNP-OB cocultures (Figure 7C). Interestingly, we found that EphB4-Fc completely inhibited the increased OCN expression induced by MVNP OCLs. To further explore this effect of EphB4-Fc on the cocultures, we measured IL-6 and IGF1 expression in the cocultures to determine whether reverse signaling through ephrin $\mathrm{B} 2$ induced by EphB4-Fc decreased IL-6 and IGF1 expression in MVNP OCLs. As shown in Supplemental Figure 5, addition of EphB4-Fc (5 $\mu \mathrm{g} /$ $\mathrm{ml}$ ) decreased the levels of IL- 6 and IGF1 in the cocultures of OCLs and OBs from WT and MVNP mice, using the same culture conditions as in Figure 3C.

We next determined whether the effects of blocking signaling pathways known to be activated when IGF1 binds the IGF1R in human OCLs decreases both the expression of ephrinB2 and the downstream signaling pathways activated by IGF1 in OBs from WT and MVNP mice. We found that the PI3K inhibitor (LY294002) blocked ephrinB2 expression in MVNP-expressing OCLs (Supplemental Figure 3A). OBs from MVNP mice had increased AKT and ERK activation when treated with IGF1 compared with WT OBs (Supplemental Figure 3B), suggesting a greater IGF1 responsiveness of OBs from MVNP mice compared with those from WT mice. 
A

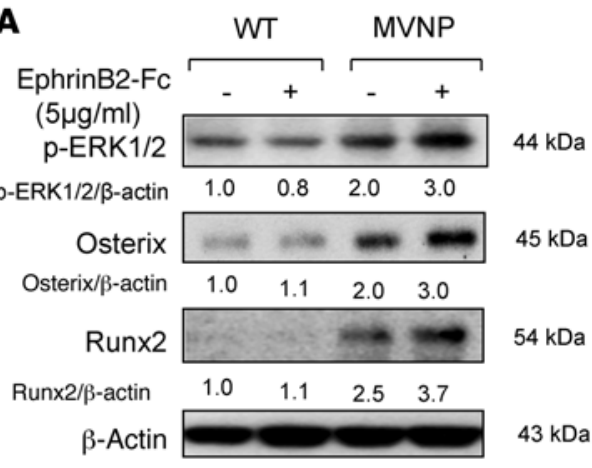

C

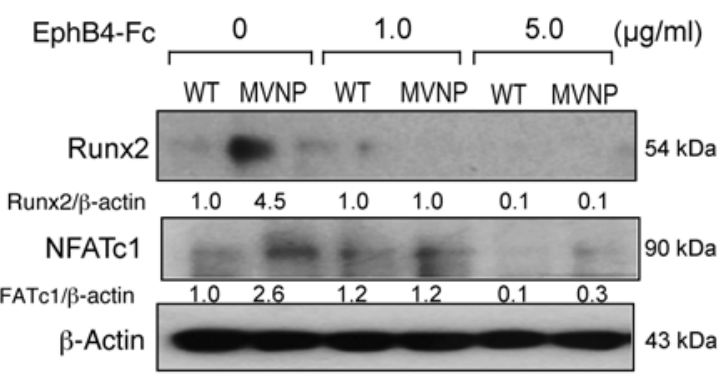

D

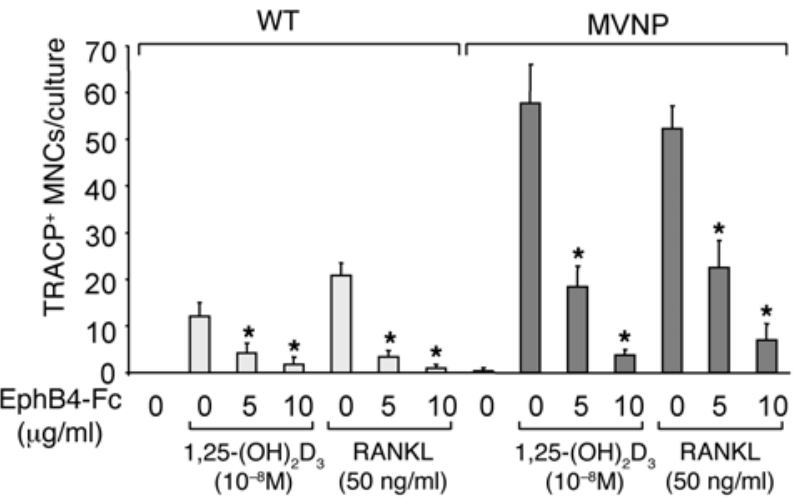

E

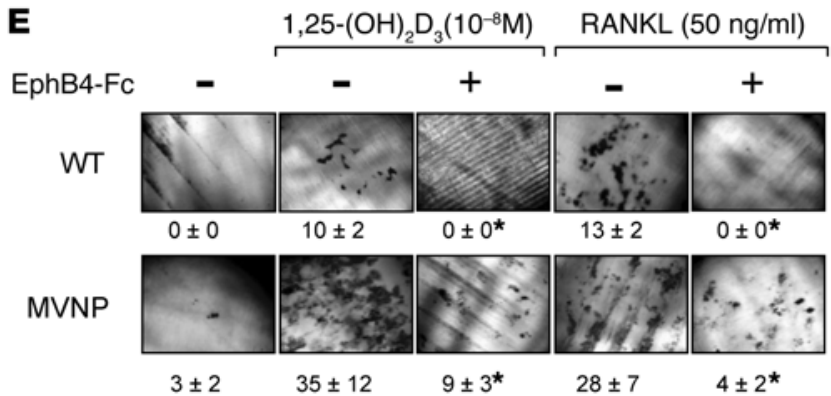

B

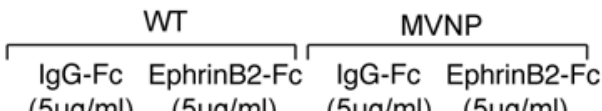
$\begin{array}{llll}(5 \mu \mathrm{g} / \mathrm{ml}) & (5 \mu \mathrm{g} / \mathrm{ml}) \quad(5 \mu \mathrm{g} / \mathrm{ml}) \quad(5 \mu \mathrm{g} / \mathrm{ml})\end{array}$

ALP
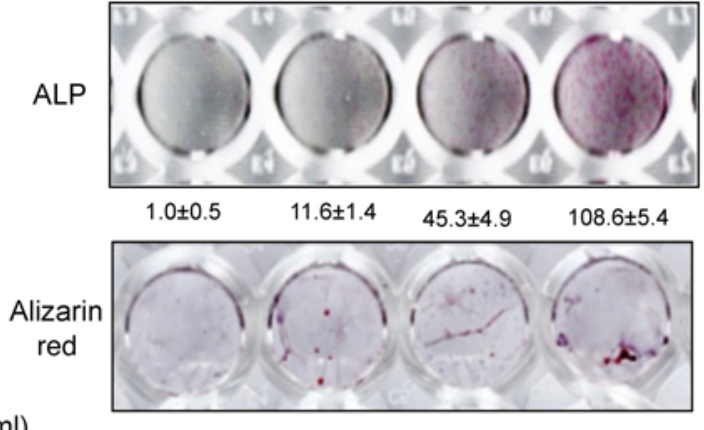

$1.0 \pm 0.1 \quad 1.5 \pm 0.1 \quad 1.2 \pm 0.2 \quad 2.9 \pm 0.1$
$\mathbf{F}$

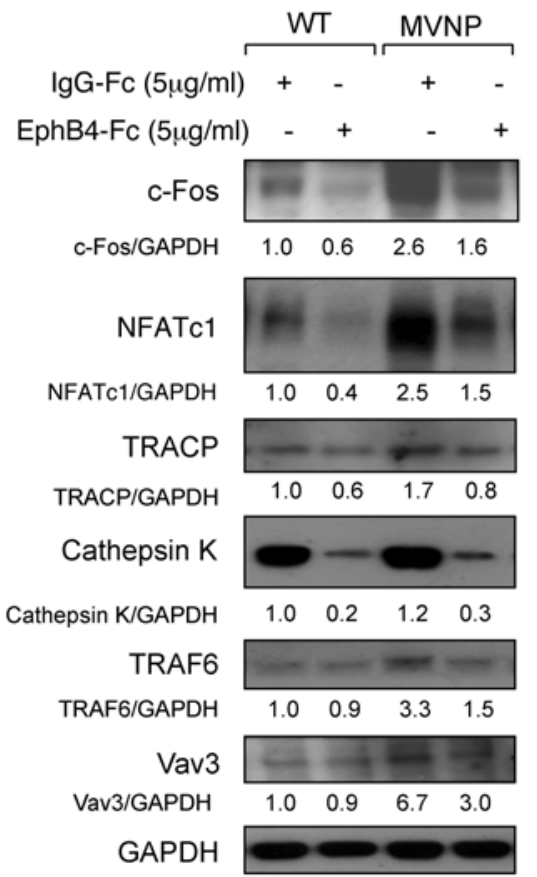

Figure 3. Effects of ephrinB2-Fc or EphB4-Fc on OB and OCL differentiation. (A) OB precursors from WT and MVNP mice were treated with ephrinB2-Fc for 4 days and analyzed for p-ERK1/2, osterix, and Runx2. (B) OBs from WT and MVNP mice were cultured with control-Fc or ephrinB2-Fc and stained for ALP or alizarin red (26). ALP and alizarin red staining was quantitated by Image software. The values for cultures treated with IgG-Fc were set at 1. Original magnification, $\times 1$. (C) Cocultures of OBs and OCLs from WT and MVNP mice were treated with EphB4-Fc for 3 days and then analyzed for Runx2 or NFATc1 expression. (D) CD11 b+ cells from WT and MVNP mice were cultured with M-CSF, followed by $1,25-(\mathrm{OH})_{2} \mathrm{D}_{3}$ or RANKL and EphB4-Fc or IgG-Fc and stained for TRACP. Data represent the mean $\pm \mathrm{SD}$. ${ }^{*} P<0.01$ compared with cultures with IgG-Fc using 1-way ANOVA. (E) Resorption pits formed on dentin slices by OCLs cultured with $1,25-(\mathrm{OH})_{2} \mathrm{D}_{3}$ or RANKL with or without EphB4-Fc. Original magnification, $\times 250$. Data are expressed as the percentage of resorption area (mean $\pm S D ; n=4$ technical replicates). ${ }^{*} P<0.01$ compared with control cultures using a 2-tailed, unpaired Student's $t$ test. (F) CD11 $\mathrm{b}^{+}$ cells were cultured with EphB4-Fc or control IgG-Fc as described in Methods. Cell lysates were analyzed for c-Fos, NFATc1, TRACP, cathepsin K, TRAF6, and Vav3. Protein expression levels in Figure 3 were compared with $\beta$-actin or GAPDH by densitometry. The value of the ratio obtained in lysates from untreated WT OCLs compared with $\beta$-actin or GAPDH was arbitrarily set at 1 . Results for Figure 3 (except E) are representative of 3 biological replicates. 
A

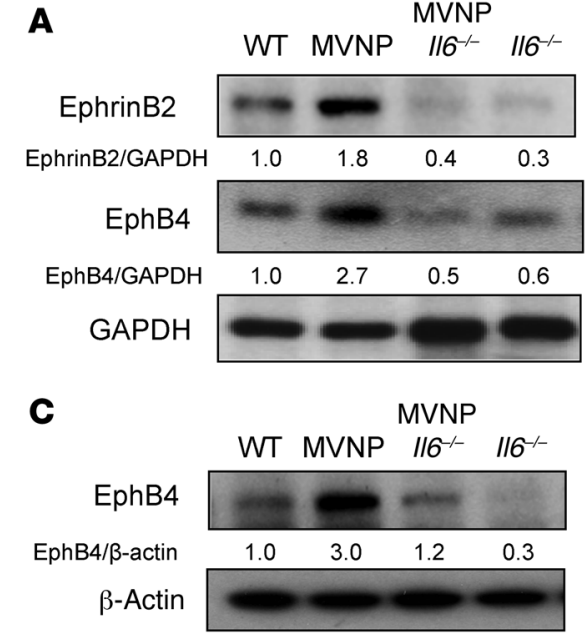

E
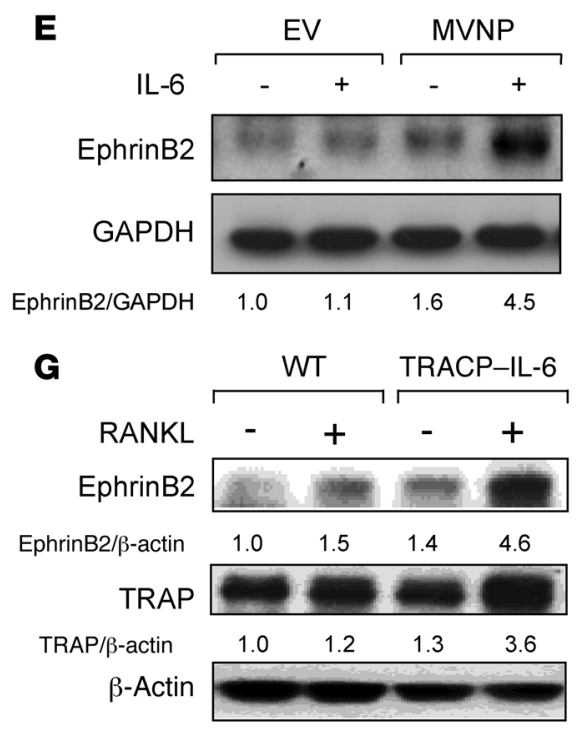

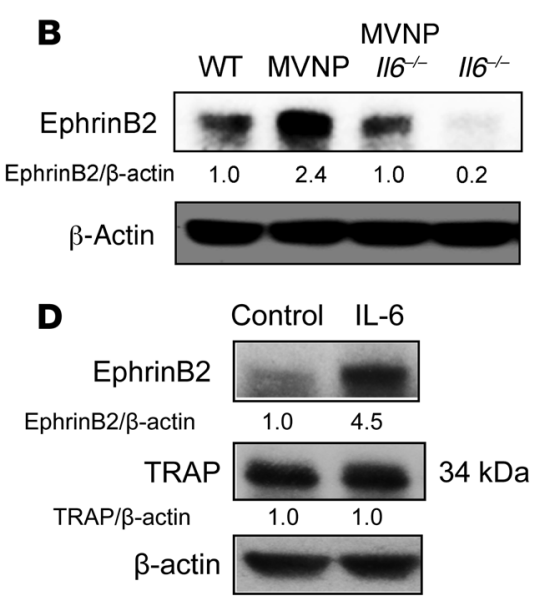

$\mathbf{F}$

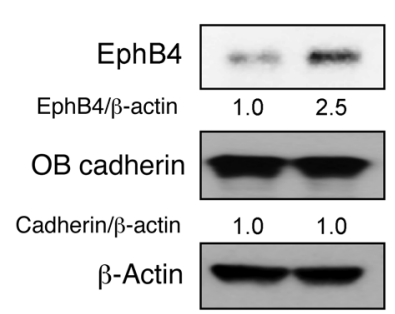

Figure 4. Effect of IL-6 on ephrinB2 and EphB4 expression by OCLs and OBs. (A) Bone extracts were analyzed for ephrinB2 and EphB4 proteins. (B) OCLs from CD11b marrow cells from 8-month-old WT, MVNP, MVNP $1 / 6^{-1-}$, and $1 / 6^{-1-}$ mice were analyzed for ephrinB2 expression. (C) Cell lysates from $\mathrm{OBs}$ derived from WT, MVNP, MVNP $I / 6^{-/-}$, and $/ 16^{-/-}$mice were prepared as previously described (26) and analyzed for EphB4 expression. (D) CD11b+ cells from WT mice were cultured with M-CSF for 3 days, treated with IL- 6 for 4 days, and analyzed for ephrinB2 expression. (E) Human OCL precursors transduced with EV or MVNP, as previously described (34), were cultured with RANKL, then treated with IL-6 $(10 \mathrm{ng} / \mathrm{ml})$ for 3 days and tested for ephrinB2 expression. (F) OBs prepared as described previously (26) were treated with IL-6 for 3 days and then analyzed for EphB4 expression. (C) OCLs from CD11b+ cells of WT and TRACP-IL-6 mice were analyzed for ephrinB2 expression. The basal ratio of every molecule/loading control for vehicle treatment of WT cells was set at 1 in $\mathbf{A}-\mathbf{C}$. All results are representative of 3 biological replicates.

that their OCLs expressed high levels of ephrinB2, while their OBs expressed its receptor EphB4 in vivo. Further, our studies with OCLs derived from CD11 $\mathrm{b}^{+}$ cells from WT, MVNP, p62-KI, and p62KI MVNP mice showed that ephrinB2 was only increased in MVNP-expressing OCLs (Figure 1E). These data suggest that MVNP expression in OCLs, either alone or in combination with $\mathrm{p} 62^{\mathrm{P} 394 \mathrm{~L}}$, but not $\mathrm{p} 62^{\mathrm{P} 394 \mathrm{~L}}$ alone, enhances ephrinB2 expression by OCLs and that enhanced ephrinB2/EphB4 signaling contributes to the abnormal bone formation seen in PD.

Enhanced EphB4 expression in OBs correlated with increased Runx2 expression in OBs from MVNP mice (Figure 3). In contrast, ephrinB2 expression was not increased in OBs from MVNP mice (data not shown). The ephrinB2 signaling in OBs has been reported to enhance OB differentiation and mineralization (22). These results suggest that in PD, MVNP expression in OCLs induces EphB4 expression on OBs to enhance OCLdriven OB activity.

To determine whether ephrinB2 was increased in PD patients, we tested OCL precursors from PD patients who harbored the p62 $2^{\mathrm{P} 392 \mathrm{~L}}$ mutation and did or did not express $\operatorname{MVNP}(12,13,23)$. To circumvent the difficulty of obtaining marrow samples from PD patients, we assayed ephrinB2 expression in OCL precursors isolated from the peripheral blood of PD patients who we previously confirmed did or did not express MVNP in their marrow-derived OCLs and compared these OCL precursors with those from 2 age-matched controls. We previously reported that very low numbers of peripheral blood cells from MVNP-positive PD patients have detectable MVNP levels (24). Similarly, Neale and coworkers showed that circulating OCL precursors from pagetic-like OCL mass to induce new bone formation. Immunohistochemical analysis of bones from MVNP mice confirmed 
A

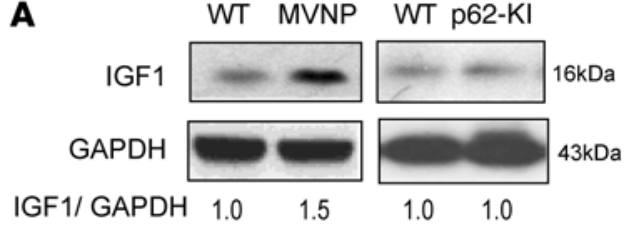

B

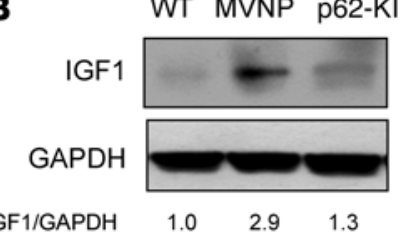

C

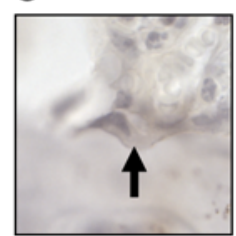

WT

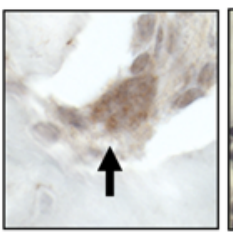

MVNP

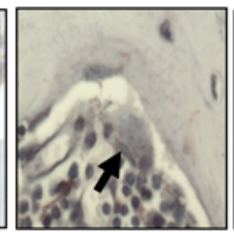

p62-KI

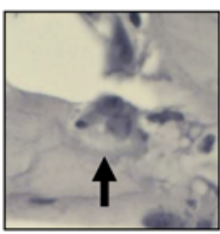

MVNP

IgG control

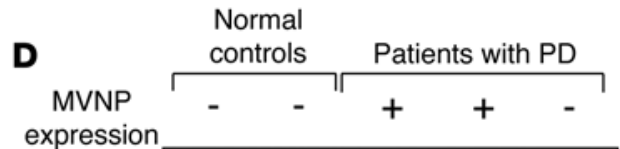

expression

IGF1

GAPDH

IGF1/GAPDH

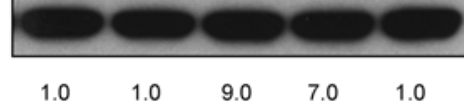

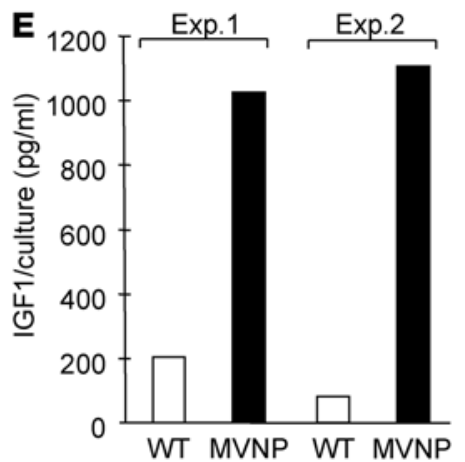

$\mathbf{F}$ IGF1 (ng/ml) $\begin{array}{lllllll} & 0 & 10 & 100 & 0 & 10 & 100\end{array}$

EphrinB2

$\begin{array}{lllllll}\text { EphrinB2/GAPDH } & 1.0 & 1.2 & 0.5 & 1.4 & 2.5 & 1.5\end{array}$

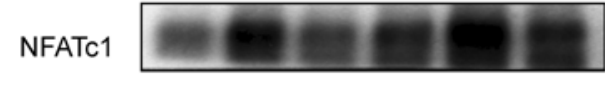

$\begin{array}{lllllll}\text { NFATc1/GAPDH } & 1.0 & 2.2 & 0.5 & 1.5 & 3.6 & 1.8\end{array}$

GAPDH

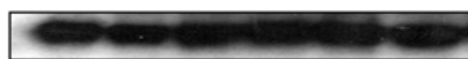

G

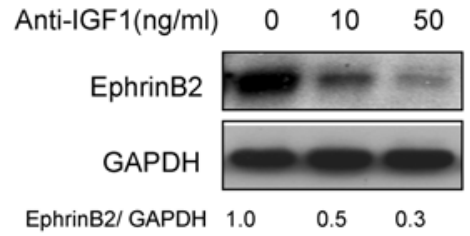

H

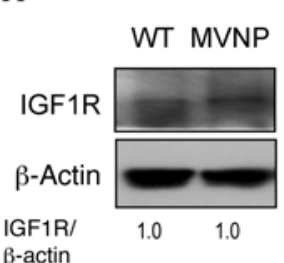

I IGF1

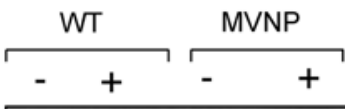

Runx2
IGF1R/ $\beta$-actin

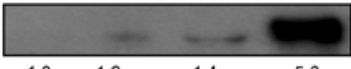

\section{EphB4}

EphB4/ק-actin

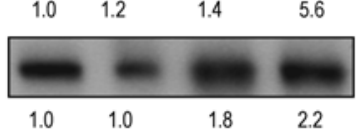

$\beta$-Actin

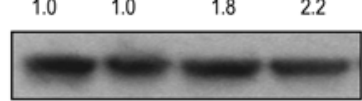

Figure 5. Increased IGF1 expression by MVNP-expressing OCLs. (A) Bone lysates were analyzed for IGF1 expression. (B) OCLs formed by CD11b ${ }^{+}$ cells from 8-month-old WT, MVNP, and p62-KI mice were analyzed for ICF1 expression. (C) Vertebral sections from 12-month-old WT, p62-KI, and MVNP mice were stained with anti-IGF1 or control IgG. Only OCLs from MVNP mice positively stained for IGF1. Original magnification, $\times 400$. (D) IGF1 expression in OCLs from normal donors or patients with PD. The results shown in $\mathbf{D}$ are derived from the same gel shown in Figure 2. (E) IGF1 levels in OCL-conditioned media using an ELISA kit. Results represent the mean of 5 technical replicates from 2 biological replicates. (F) EphrinB2 and NFATc-1 expression in OCLs formed by CD11b+ cells treated with IGF1 for 4 days. (C) OCLs from PD patients were cultured with anti-IGF1 for 48 hours and the cell lysates assayed for ephrinB2 expression. (H) IGF1R expression on OCLs formed by CD11b+ cells were prepared as in B. (I) OBs were prepared as described previously (26), cultured with IGF1 for 3 days, and analyzed for EphB4 or Runx2 expression. Results for Figure 5 (except E) are representative of 3 biological replicates. The basal ratio of every molecule/loading control for vehicle treatment of WT cells was set at 1.0 in A, B, D, and F-I. Staining of OCLs from MVNP and WT mice (scored as positive or negative) showed positive anti-IGF1 staining in OCLs from MVNP, but not WT, mice.

PD patients expressed features similar to those seen in marrowderived OCL precursors, including increased responsivity to RANKL and 1,25- $(\mathrm{OH})_{2} \mathrm{D}_{3}(25)$. As we previously reported, MVNP was detectable in peripheral blood-derived OCLs from 2 patients who expressed MVNP in OCLs formed in marrow cultures and was not detectable in a PD patient who did not express MVNP (13). We cannot determine from our experiments whether all the circulating OCL precursors in MVNP-positive PD patients express MVNP or whether only a subpopulation of these precursors express MVNP.
Only OCLs derived from $\mathrm{p} 62^{\mathrm{P} 392 \mathrm{~L}}$-harboring PD patients expressing MVNP had increased levels of ephrinB2 (Figure 2). These results are consistent with our hypothesis that ephrinB2 increases new bone formation in PD patients expressing MVNP.

We next determined whether increased expression of EphB4 by OBs from MVNP mice enhanced OB differentiation. Stimulation of forward signaling with ephrinB2-Fc through EphB4 markedly enhanced OB differentiation in OBs derived from MVNP, but not WT, mice (Figure 3, A and B). Further, forward signaling 
A

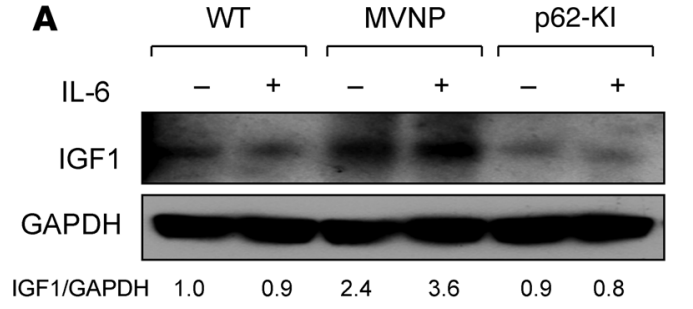

B

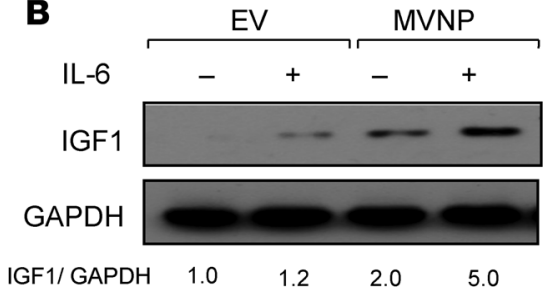

C

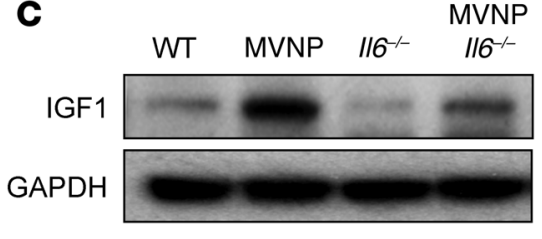

$\begin{array}{lllll}\text { IGF1/GAPDH } \quad 1.0 & 4.5 & 0.8 & 1.8\end{array}$
Figure 6. IL-6 increases IGF1 expression in MVNP-expressing OCLs. (A) OCLs formed by CD11b+ cells from 8-month-old WT, MVNP, and p62-KI mice were treated with IL-6 $(10 \mathrm{ng} / \mathrm{ml})$ for 4 days and cell lysates analyzed for IGF1 expression. (B) OCLs from normal human OCL precursors transduced with EV or MVNP retroviral constructs were treated with IL-6 $(10 \mathrm{ng} / \mathrm{ml})$ for 4 days and assayed for IGF1 expression. Results shown in $\mathbf{B}$ are derived from the same gel shown in Figure 4E. (C) IGF1 expression by OCLs formed by CD11 b ${ }^{+}$cells from 8-month-old mice. The basal ratio of every molecule/loading control for vehicle treatment of WT cells was set at 1.0 in A-C. Results are representative of 3 biological replicates. through EphB4 enhanced ERK1/2 signaling and osterix expression (Figure 3A), both of which have been shown to mediate EphB4 signaling in OBs to increase bone mass in transgenic mice (15).

We then measured the effects of stimulating reverse signaling through ephrinB2 with varying concentrations of EphB4-Fc on the differentiation of OCL precursors from MVNP and WT mice and in cocultures of OCLs and OBs. As expected, EphB4-Fc blocked OB differentiation (Figure 3C) and suppressed OCL differentiation by inhibiting the c-Fos/NFATc1 cascade (Figure 3, $\mathrm{D}-\mathrm{F})$, as reported in other models (16). Interestingly, EphB4-Fc treatment also decreased IL-6 and IGF1 expression in these cocultures. These data support the hypothesis that increased ephrinB2/ EphB4 signaling induced by MVNP in OCLs plays a major role in coupling between bone resorption and new bone formation in PD and that suppressing OCL differentiation by inducing reverse signaling through ephrinB2 decreases the enhanced IL-6 and IGF1 production induced by MVNP expressions in OCLs.

We next determined the mechanisms responsible for the increased expression of ephrinB2 and EphB4 in MVNP mice. We found that loss of IL-6 expression in MVNP mice, which blocks induction of pagetic-like OCLs and pagetic-like bone lesions (13), also downregulated ephrinB2 expression on OCLs and EphB4 on OBs from MVNP mice (Figure 4, A-C). Interestingly, our studies with TRACP-IL-6 mice, which do not develop pagetic lesions or increased bone formation in vivo or pagetic OCLs in vitro (26), showed that ephrinB2 is increased on OCLs from these mice. These results suggest that IL- 6 is necessary, but not sufficient, to induce increased OB activity in MVNP mice and that other factors induced by MVNP in addition to IL- 6 are also required to increase OB activity in vivo.

To identify other factors contributing to the increased OB activity in MVNP mice, we performed a preliminary gene expression-profiling study of highly purified OCLs from MVNP, p62-KI, and WT mice and found that OCLs from MVNP mice express elevated levels of Igf1 mRNA, while OCLs from WT and p62-KI mice do not. We confirmed that IGF1 production at the protein level was increased in MVNP-expressing OCLs in vitro and in vivo (Figure 5, A-C). Moreaux et al. have also recently reported IGF1 production by OCLs in patients with myeloma, who, like PD patients, have increased IL- 6 production in the marrow microenvironment (27). However, unlike PD, in which IGF1 appears to increase bone formation, IGF1 produced by OCLs in myeloma does not increase bone formation, because myeloma cells also produce OB inhibitors.

The amount of IGF1 induced by MVNP-expressing OCLs is considerable. Assays of conditioned media from OCL cultures from MVNP and WT mice showed that the nanogramper-milliliter quantities of IGF1 were produced by the MVNPexpressing OCLs and that MVNP-expressing OCLs had the highest production of IGF compared with that found in p62-KI or WT mice (Figure 5, D and E). These results suggest that OCLs, rather than OBs, are the major producers of local IGF1 in PD. IGF1 has recently been reported to be essential for normal bone mineralization. OB-specific KO of the IGF1R resulted in a striking decrease in cancellous bone volume, connectivity, and trabecular number and an increase in trabecular spacing (28), suggesting an important role for IGF1 in normal bone formation (29). Our findings suggest that OCL-derived IGF1 may also play an important role in the pathologic, rapid new bone formation that occurs in $\mathrm{PD}$, since IGF1 increased expression of ephrinB2 on OCLs and increased OB differentiation. These data suggest that increased IGF1 expression and upregulation of ephrinB2 and EphB4 induced by MVNP may drive the enhanced bone formation seen in PD and that OBs from patients with PD may have increased responsivity to IGF1.

To further dissect the role of IL- 6 in mediating the increase in ephrinB2 on OCLs, we treated WT OCLs with $10 \mathrm{ng} / \mathrm{ml} \mathrm{IL-6}$ in vitro to determine whether ephrinB2 or IGF1 was upregulated. IL-6 enhanced the expression of both ephrinB2 (Figure 4E) and IGF1 (Figure 6A). These results demonstrate that IL-6 regulates ephrinB2 and IGF1 in OCLs.

We then determined whether IGF1 induced by IL- 6 is responsible for the increase in ephrinB2 and EphB4 in MVNP mice. IGF1 increased ephrinB2 on OCLs and Runx2 in OBs (Figure 5F and I), and ephrinB2 was decreased by anti-IGF1 Ab in MVNPexpressing OCLs (Figure 5G). Our findings demonstrate that IGF1 induced by IL- 6 increases ephrinB2 on OCLs from MVNP mice and that OCLs express the IGF1R (Figure 5H). Consistent with our results, Wang et al. reported that mice lacking the IGF1R in their OCLs have decreased ephrinB2 levels (30). However, their experiments did not address whether IGF1 is expressed in OCLs 

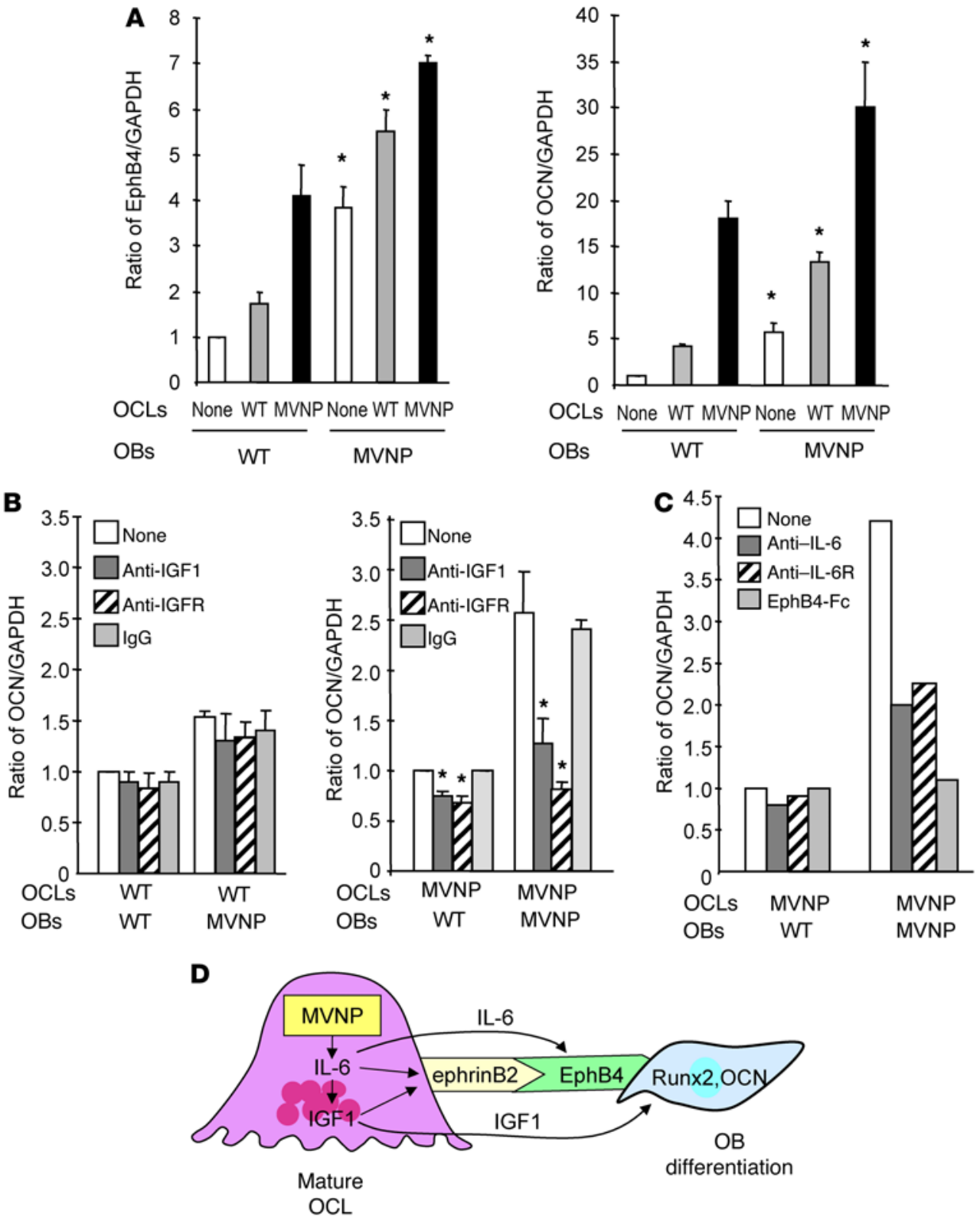

or whether OCL-derived IGF1 induces ephrinB2 on OCLs. Our results demonstrate that IGF1 is expressed by OCLs containing MVNP and induces ephrinB2. The finding that there is still residual ephrinB2 expression in MVNP-expressing OCLs treated with high levels of anti-IGF1 (Figure 5C) suggests that an additional factor induced by MVNP may also contribute to the increase in ephrinB2 expression.

Our results suggest that IGF1 produced by OCLs is also required for the enhanced bone formation seen in PD. As shown in Figure 7D, coculture of OCLs from MVNP or WT mice with OB precursors from WT mice in the presence of saturating concentrations of anti-IGF1 or anti-IGF1R demonstrated that both anti-IGF1 and anti-IGF1R blocked the enhanced OB differentiation induced by MVNP-expressing OCLs (Figure 7B).

In summary, MVNP expression in OCLs from MVNP mice and PD patients increases IL- 6 production, which upregulates expression of ephrinB2 and IGF1 in OCLs and EphB4 in OBs. IGF1 induced by IL- 6 in turn upregulates ephrinB2 and increases OB differentiation. These experiments provided important new insights into the regulation of OB activity by OCLs and the mechanisms responsible for the induction of coupling factors in OCLs and OBs in PD. These results further suggest that enhanced coupling factor expression and increased IGF1 production by pagetic OCLs are major contributors to the rapid bone formation that occurs in PD.

\section{Methods}

Abs and reagents. Abs used for detection of ephrinA2, ephrinB1, ephrinB2, EphA2, EphB3, EphB4, IGF1, IGF1R, MVNP, osterix, Vav3, and $\beta$-actin on Western blots were purchased from Abcam, and Runx2, NFATc-1, c-Fos, TRACP, cathepsin K, TRAF6, IL-6, and semaphorin $3 \mathrm{~A}$ Abs were purchased from Santa Cruz Biotechnology Inc. Antiosteocalcin was purchased from EMD Millipore. Neutralizing Abs against IGF1, blocking Abs against IGF1R, EphB4-Fc, ephrinB2-Fc, and control IgG-Fc Abs were purchased from R\&D Systems. Abs recogniz- 
ing p-AKT, AKT, p-ERK, ERK, OB-cadherin, and GAPDH on Western blots were purchased from Cell Signaling Technology. The PI3K inhibitor LY294002 was purchased from Sigma-Aldrich.

Patients and age-matched healthy controls. Heparinized peripheral blood (50 ml) was obtained by J.P. Brown from 3 patients with familial $\mathrm{PD}$ carrying the $\mathrm{p} 62^{\mathrm{P} 392 \mathrm{~L}}$ mutation and 2 age-matched controls, shipped at room temperature overnight, and nonadherent mononuclear cells (MNCs) were prepared as described previously (6) for OCL formation assays immediately after receipt. Nonadherent MNCs were then cultured with granulocyte-macrophage-CSF (GM-CSF) $(10 \mathrm{ng} / \mathrm{ml}) \alpha \mathrm{MEM}$ containing $10 \%$ FCS for 7 days, and then the media were changed to aMEM containing 20\% horse serum with RANKL (50 ng/ml) for 2 weeks as previously described (6). OCLs were enriched and cell lysates assayed for protein expression as described below. The extent and clinical activity of PD were previously documented by bone scans, pelvic $\mathrm{x}$-rays, and total alkaline phosphatase (ALP) measurements (13). PD was similarly ruled out in the controls.

Preparation of bone lysates for protein analysis. Tibiae and femurs were dissected from mice, frozen immediately in liquid nitrogen, and reduced to powder using a small mortar and pestle. Total proteins were extracted in lysis buffer overnight at $4^{\circ} \mathrm{C}$, and $25 \mu \mathrm{g}$ protein/lane was subjected to immunoblot analysis using the appropriate Abs as follows: lysates were run on precast SDS polyacrylamide gels, transferred to nitrocellulose membranes, the membranes stained with Ponceau S, and the membranes cut into strips on the basis of the molecular weight markers. The selected strips were incubated with blocking solution ( $5 \%$ nonfat dry milk in Trisbuffered saline/Tween-20 [TBST]) for 1 hour, exposed to primary Abs overnight at $4^{\circ} \mathrm{C}$, and incubated with IgG HRP-conjugated $\mathrm{Ab}$ for 1 hour. The blots were washed and visualized by an Immobilon Western Chemiluminescence detection system (EMD Millipore). Protein expression levels were quantitated by densitometry using ImageJ software (NIH).

Generation of MVNP, p62-KI, p62-KI MVNP, MVNP Il6-/, and $I L-6$ mice. Transgenic mice expressing MVNP under the control of the mouse TRACP promoter were previously described (20), as were KI mice carrying a proline-to-leucine substitution at residue 394 of the endogenous mouse SQSTM1/p62 gene (equivalent to human $\left.\mathrm{p} 62^{\mathrm{P} 392 \mathrm{~L}}\right)$ (12). All data are from mice generated from this $\mathrm{p} 62^{\mathrm{P} 394 \mathrm{~L}}$ MVNP colony (not from the parental p62 $2^{\mathrm{P} 394 \mathrm{~L}}$ or MVNP colonies). Global $I l 6^{-1-}$ mice were generated by Kopf et al. (31) and obtained from The Jackson Laboratory (stock 002650). Mice were interbred with MVNP mice as above. All data are from mice generated from this $I l 6^{-/-}$MVNP colony (not from the parental colonies). Transgenic mice expressing IL-6 under control of the mouse TRACP promoter were previously described (26).

OCL formation from purified OCL precursors. Nonadherent marrow cells were harvested and enriched for CD11b $\mathrm{b}^{+} \mathrm{MNCs}$ using the Miltenyi Biotec MACS magnetic cell-sorting system. OCL formation from $\mathrm{CD} 11 \mathrm{~b}^{+}$cells was then performed as described previously (13) in the presence of $1,25-(\mathrm{OH})_{2} \mathrm{D}_{3}$ or RANKL to generate OCLs. The cells were stained for TRACP, and TRACP-positive multinucleated cells ( $\geq 3$ nuclei/cell) were scored as OCLs.

Bone resorption assays of cultured OCLs. Bone marrow cells were cultured on mammoth dentin slices (Wako) in aMEM containing $10 \% \mathrm{FCS}$ and $1,25-(\mathrm{OH})_{2} \mathrm{D}_{3}\left(1 \times 10^{-8} \mathrm{M}\right)$ or RANKL $(100 \mathrm{ng} / \mathrm{ml})$. After 14 days of culture, the cells were removed, the dentin slices stained with acid hematoxylin, and the areas of dentin resorption determined using image analysis techniques (ImageJ) (32).

Immunoblotting of OCL lysates from WT, MVNP, p62-KI, p62KI MVNP, MVNP Il6 ${ }^{--}, I l^{-/}$, and IL-6 mice. Total proteins were extracted from OCLs formed from OCL precursors and the cell lysates $(10 \mu \mathrm{g} /$ lane $)$ loaded on SDS gels using the Bio-Rad Mini-PROTEAN Precast Gels. The resolved proteins were transferred onto nitrocellulose membranes (TGX Membrane; Bio-Rad) using the Trans-Blot Turbo Transfer System (Bio-Rad), then the membranes were stained with Ponceau S, cut into strips on the basis of the molecular weight markers, and processed as described above for bone lysates using the appropriate Abs.

Isolation of mature OCLs from mouse bone marrow cultures. Bone marrow cells flushed from long bones of WT, p62-KI, IL-6, MVNP $I l 6^{-/}$, and MVNP mice were cultured in a $10-\mathrm{cm}$ dish $\left(2.5 \times 10^{7}\right.$ cells/ dish) with M-CSF (10 ng/ml) (R\&D Systems) for 3 days and RANKL (50 ng/ml) (R\&D Systems) for 4 days as previously described (20). At the end of culturing, trypsin EDTA (Corning) was added and the cultures incubated for 3 minutes to remove nonosteoclastic cells and enrich the concentration of OCLs in the cultures.

Coculture of OCLs and OBs from WT and MVNP mice. OCLs $\left(2 \times 10^{4} /\right.$ well) derived from cultures of MVNP or WT mouse OCL precursors were scraped with a rubber policeman as described above, replated, and cultured with $50 \mathrm{ng} / \mathrm{ml}$ RANKL overnight. The OBs $\left(1 \times 10^{5} /\right.$ well $)$ described above were plated on top of the OCLs the next day, and the cells were cocultured for 72 hours (Supplemental Figure 4).

IGF1 ELISA assays. Mouse OCLs were isolated as described above $\left(2 \times 10^{4} / \mathrm{ml}\right)$ and cultured with RANKL for 4 days. Conditioned media from these cultures were harvested at the end of the culture period and the concentration of IGF1 determined using an ELISA kit for mouse IGF1 (Abcam) according to the manufacturer's instructions.

IHC analyses. The first to fourth lumbar vertebrae from 12-month-old WT and transgenic mice were fixed in 10\% buffered formalin and completely decalcified in $10 \%$ EDTA at $4^{\circ} \mathrm{C}$ and embedded in paraffin. Five-micrometer longitudinal sections were cut and mounted on glass slides. Deparaffinized sections were treated with $1 \%$ horse serum for 1 hour, followed by primary Abs against ephrinB2 and EphB4 (both from Abcam) or control IgG. The sections were incubated overnight and then stained with anti-rabbit IgG conjugated to peroxidase (Vector Laboratories).

Isolation and culture of primary OBs. After flushing the bone marrow from tibiae of MVNP and WT mice, the tibiae were cultured in $\alpha$ MEM containing $10 \%$ FCS for 7 to 10 days. The bones were then placed in $60-\mathrm{mm}$ dishes, and the cultures were continued in $\alpha \mathrm{MEM}$ containing $10 \%$ FCS until cells growing out of the bones formed a confluent monolayer. The original bone was removed, and the outgrowth cells from the bone were treated with $0.25 \%$ trypsin and $0.05 \%$ EDTA for 10 minutes at $37^{\circ} \mathrm{C}$. These cells were used as primary OBs without further passage. The primary OBs $\left(2 \times 10^{5}\right.$ cells/ well in 6-well plates) were cultured in $\alpha$ MEM containing $10 \%$ FCS for 7 to 14 days. Cells were stained for ALP or alizarin red, or cell lysates were collected and analyzed for protein expression, as previously described (26).

Statistics. Significance was evaluated using a 2-tailed, unpaired Student's $t$ test. When more than 2 treatment groups were compared, 1-way ANOVA for repeated measures was used. A $P$ value of less than 0.05 was considered significant. 
Study approval. Human studies were approved by the Indiana University and Laval University human studies committees. All patients provided informed consent prior to participation in the study, in accordance with the Declaration of Helsinki principles. Animal studies were approved by the IACUCs of VCU and the Indiana University School of Medicine.

\section{Author contributions}

GDR and NK designed the study, interpreted the data, and wrote the manuscript. JT, YN, YI, YO, and NK performed the experiments. JJW generated the transgenic mice and helped write the manuscript. KM and TG performed histological studies and analyses. LM and JPB identified the PD patients and the appropriate controls and provided peripheral blood from the PD patients and the controls. All authors approved the submission of the manuscript.

\section{Acknowledgments}

This work was supported by grants from the National Institute of Arthritis and Musculoskeletal and Skin Diseases (NIAMS), NIH (R01-AR057308, to G.D. Roodman); the National Cancer Institute (NCI), NIH (5P30CA016059, to J.J. Windle); and the US Department of Defense (W81XWH-12-1-0533, to N. Kurihara). The mice for this research were provided by the VCU Transgenic/Knock-out Mouse Shared Resource.

Address correspondence to: G. David Roodman, Department of Medicine, Hematology/Oncology, School of Medicine, Indiana University, 980 West Walnut Street, Suite C312, Indianapolis, Indiana 46204, USA. Phone: 317.278.6255; E-mail: groodman@iu.edu.
1. Basle M, Minard MF, Rebel A. [Structure and ultrastructure of osteoblasts and of the osteoid tissue in Paget's disease of bone (author's transl)]. Pathol Biol (Paris). 1978;26(8):475-479.

2. Zajac AJ, Phillips PE. Paget's disease of bone: clinical features and treatment. Clin Exp Rheumatol. 1985;3(1):75-88.

3. Rebel A, Malkani K, Basle M, Bregeon C. Osteoclast ultrastructure in Paget's disease. Calcif Tissue Res. 1976;(2):187-199.

4. Roodman GD, Windle JJ. Paget disease of bone. JClin Invest. 2005;115(2):200-208.

5. Kukita A, Chenu C, McManus LM, Mundy GR, Roodman GD. Atypical multinucleated cells form in long-term marrow cultures from patients with Paget's disease. JClin Invest. 1990;85(4):1280-1286.

6. Kurihara N, et al. Role of TAFII-17, a VDR binding protein, in the increased osteoclast formation in Paget's Disease. J Bone Miner Res. 2004;19(7):1154-1164.

7. Menaa C, et al. Enhanced RANK ligand expression and responsivity of bone marrow cells in Paget's disease of bone. JClin Invest. 2000;105(12):1833-1838.

8. Roodman GD, et al. Interleukin 6. A potential autocrine/paracrine factor in Paget's disease of bone. J Clin Invest. 1992;89(1):46-52.

9. Morissette J, Laurin N, Brown JP. Sequestosome 1: mutation frequencies, haplotypes, and phenotypes in familial Paget's disease of bone. J Bone Miner Res. 2006;21(suppl 2):P38-P44.

10. Laurin N, Brown JP, Morissette J, Raymond V. Recurrent mutation of the gene encoding sequestosome 1 (SQSTM1/p62) in Paget disease of bone. Am J Hum Genet. 2002;70(6):1582-1588.

11. Hocking LJ, et al. Domain-specific mutations in sequestosome 1 (SQSTM1) cause familial and sporadic Paget's disease. Hum Mol Genet. 2002;11(22):2735-2739.

12. Hiruma Y, et al. A SQSTM1/p62 mutation linked to Paget's disease increases the osteoclastogenic potential of the bone microenvironment. Hum Mol Genet. 2008;17(23):3708-3719.

13. Kurihara N, et al. Contributions of the measles virus nucleocapsid gene and the SQSTM1/ p62(P392L) mutation to Paget's disease. Cell Metab. 2011;13(1):23-34.

14. Matsuo K, Otaki N. Bone cell interactions through Eph/ephrin: bone modeling, remodeling and associated diseases. Cell Adh Migr. 2012;6(2):148-156.

15. Zhao C, et al. Bidirectional ephrinB2-EphB4 signaling controls bone homeostasis. Cell Metab. 2006;4(2):111-121.

16. Edwards CM, Mundy GR. Eph receptors and ephrin signaling pathways: a role in bone homeostasis. Int J Med Sci. 2008;5(5):263-272.

17. Irie $\mathrm{N}$, et al. Bidirectional signaling through ephrinA2-EphA2 enhances osteoclastogenesis and suppresses osteoblastogenesis. J Biol Chem. 2009;284(21):14637-14644.

18. Martin TJ, et al. Communication between ephrinB2 and EphB4 within the osteoblast lineage. Adv Exp Med Biol. 2010;658:51-60.

19. Allan EH, et al. EphrinB2 regulation by PTH and PTHrP revealed by molecular profiling in differentiating osteoblasts. J Bone Miner Res. 2008;23(8):1170-1181.

20. Kurihara N, et al. Expression of measles virus nucleocapsid protein in osteoclasts induces Paget's disease-like bone lesions in mice. J Bone Miner Res. 2006;21(3):446-455.

21. Hayashi M, Nakashima T, Taniguchi M, Kodama T, Kumanogoh A, Takayanagi H. Osteoprotection by semaphorin 3A. Nature. 2012;485(7396):69-74.

22. Tonna S, et al. EphrinB2 signaling in osteoblasts promotes bone mineralization by preventing apoptosis. FASEB J. 2014;28(10):4482-4496.

23. Kurihara $\mathrm{N}$, et al. Mutation of the sequestosome 1 (p62) gene increases osteoclastogenesis but does not induce Paget disease. J Clin Invest. 2007;117(1):133-142.

24. Reddy SV, Singer FR, Mallette L, Roodman GD. Detection of measles virus nucleocapsid transcripts in circulating blood cells from patients with Paget disease. J Bone Miner Res. 1996;11(11):1602-1607.

25. Neale SD, Smith R, Wass JA, Athanasou NA.
Osteoclast differentiation from circulating mononuclear precursors in Paget's disease is hypersensitive to 1,25-dihydroxyvitamin $\mathrm{D}_{3}$ and RANKL. Bone. 2000;27(3):409-416.

26. Teramachi J, et al. Increased IL-6 expression in osteoclasts is necessary but not sufficient for the development of Paget's disease of bone. J Bone Miner Res. 2014;29(6):1456-1465.

27. Moreaux J, et al. Osteoclast-gene expression profiling reveals osteoclast-derived CCR2 chemokines promoting myeloma cell migration. Blood. 2011;117(4):1280-1290.

28. Zhang M, et al. Osteoblast-specific knockout of the insulin-like growth factor (IGF) receptor gene reveals an essential role of IGF signaling in bone matrix mineralization. J Biol Chem. 2002;277(46):44005-44012.

29. Tahimic CG, Wang Y, Bikle DD. Anabolic effects of IGF-1 signaling on the skeleton. Front Endocrinol (Lausanne). 2013;4:6.

30. Wang Y. Ephrin B2-EphB4 Bidirectional Signaling Mediates the Actions of IGF-1 Signaling in Regular Chondrocyte Osteoclast Differentiation. Presented at: ASBMR 2011 Annual Meeting; September 16, 2011; San Diego, California, USA. Presentation SA0214.

31. Kopf M, et al. Impaired immune and acute-phase responses in interleukin-6-deficient mice. Nature. 1994;368(6469):339-342.

32. Ishizuka S, Kurihara N, Reddy SV, Cornish J, Cundy T, Roodman GD. (23S)-25-Dehydro-1\{alpha\}-hydroxyvitamin D3-26,23lactone, a vitamin $\mathrm{D}$ receptor antagonist that inhibits osteoclast formation and bone resorption in bone marrow. Endocrinology. 2005;146(4):2023-2030.

33. Pennisi A, et al. The ephrinB2/EphB4 axis is dysregulated in osteoprogenitors from myeloma patients and its activation affects myeloma bone disease and tumor growth. Blood. 2009;114(9):1803-1812.

34. Kurihara N, Reddy SV, Menaa C, Anderson D, Roodman GD. Osteoclasts expressing the measles virus nucleocapsid gene display a pagetic phenotype. JClin Invest. 2000;105(5):607-614. 